\title{
Parametric Importance Analysis and Design Optimization of a Torque Converter Model Using Sensitivity Information
}

\author{
Joydeep Banerjee \\ University of Waterloo \\ Hadi Adibi asl \\ Univ of Waterloo \\ Nasser Lashgarian Azad \\ University of Waterloo \\ John McPhee \\ Univ of Waterloo
}

\begin{abstract}
Torque converters are used as coupling devices in automobile powertrains involving automatic transmissions. Efficient modeling of torque converters capturing various modes of operation is important for powertrain design and simulation, (Hroval and Tobler 1, Ishihara and Emori 2) optimization and control applications. Models of torque converters are available in various commercial simulation packages, Hadi et. al. 3 . The information about the effect of model parameters on torque converter performance is valuable for any design operation. In this paper, a symbolic sensitivity analysis of a torque converter model will be presented. Direct differentiation (Serban and Freeman 4) is used to generate the sensitivity equations which results in equations in symbolic form. By solving the sensitivity equations, the effect of a perturbation of the model parameters on the behavior of the system is determined. A parametric importance analysis is performed on the model: the model parameters are arranged according to their effect on the amount loss of energy during the operation of the torque converter. The radii of the pump, turbine and stator, the density of the hydraulic fluid and the exit angle of the vanes of the stator were found to have the most significant effects on the model. Using the sensitivity information, a design optimization problem is defined and solved to obtain a set of parameter values that minimizes the energy lost during the torque converter operation.
\end{abstract}

CITATION: Banerjee, J., Adibi asl, H., Lashgarian Azad, N. and McPhee, J., "Parametric Importance Analysis and Design Optimization of a Torque Converter Model Using Sensitivity Information," SAE Int. J. Passeng. Cars - Mech. Syst. 5(1): 2012, doi:10.4271/2012-01-0808.

\section{INTRODUCTION}

A very basic requirement of an automobile transmission system is the ability to accommodate discrepancies between the angular velocities of the engine flywheel and the drive shaft connected to the transmission differentials. For manual transmission systems a mechanical friction clutch is usually used to address this requirement by allowing the engine to be physically disengaged from the rest of the transmission. For automatic transmission systems a device known as the torque converter is often used as a coupling device. A torque converter allows the engine to rotate even when the wheels are slowing down by means of fluid coupling. Structurally it has three main components.

- A pump element, which is rigidly attached to the engine flywheel and under forward flow mode, pumps hydraulic fluid radially outward due to its vaned construction.

- A turbine element which is connected to the transmission and also has a vaned construction, so that the hydraulic fluid can impart momentum to the turbine.

- A stator element which is connected to the fixed body of the transmission through a one way clutch and has blades to 
deflect the fluid from the turbine, to the pump, thereby increasing the flow efficiency.

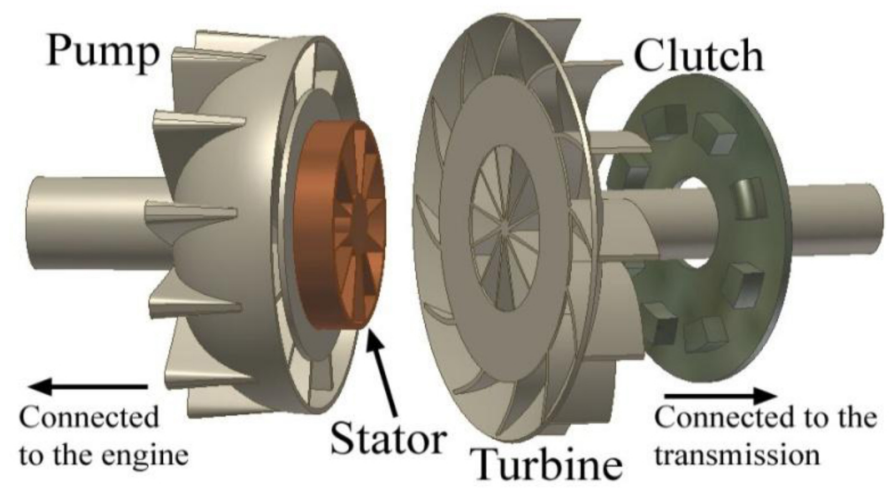

Figure 1. Axial assembly of the components of a torque converter

For this study we have worked with the model of a torque converter which captures the dynamics of components and the hydraulic fluid, (Hrovat and Tobler 1 and Hadi et. al. 3 ). In this paper we use symbolic differentiation to generate sensitivity equations from the governing equations of the model. By solving the sensitivity equations and the system equations simultaneously we obtain the state variables and the corresponding sensitivities as a function of time. Using the sensitivity information, a parametric importance analysis is performed to identify the most important parameters of the model. A design optimization problem is set up using the sensitivity information. The expression for the power loss during the operation is considered as the objective function of the optimization problem. The results section outlines the most important parameters and the optimized set of values for the parameters which minimizes the energy lost during the operation of the torque converter.

\section{MODEL DESCRIPTION}

A schematic diagram showing the motion of a fluid particle inside a typical torque converter is shown in Figure 2. The operation of a torque converter can be clearly understood by following the motion of a fluid particle around the three components: the pump (or the impeller), the turbine, and the stator.

Normally the rotational speed of the pump element is greater than that of the turbine element. The ratio of the angular velocities of the pump and the turbine is known as the speed ratio. When the speed ratio is less than unity it is known as the forward mode of operation. In the forward mode the impeller pumps hydraulic fluid radially outward through its vanes thus imparting momentum to the fluid. This momentum is transferred to the turbine when the fluid flows along the vanes of the turbine. There are two stages of operation in the forward mode. When the speed ratio is considerably less than one, the one way clutch holds the stator in place and the stator bends the flow of fluid, aligning it with the pump vanes. This way the turbine torque obtained is more than the pump torque and torque multiplication is achieved. As the speed ratio approaches unity, at one point of time, the stator torque becomes zero and the stator overruns. At this point the pump and the turbine torques are approximately equal and this is known as the coupling point.

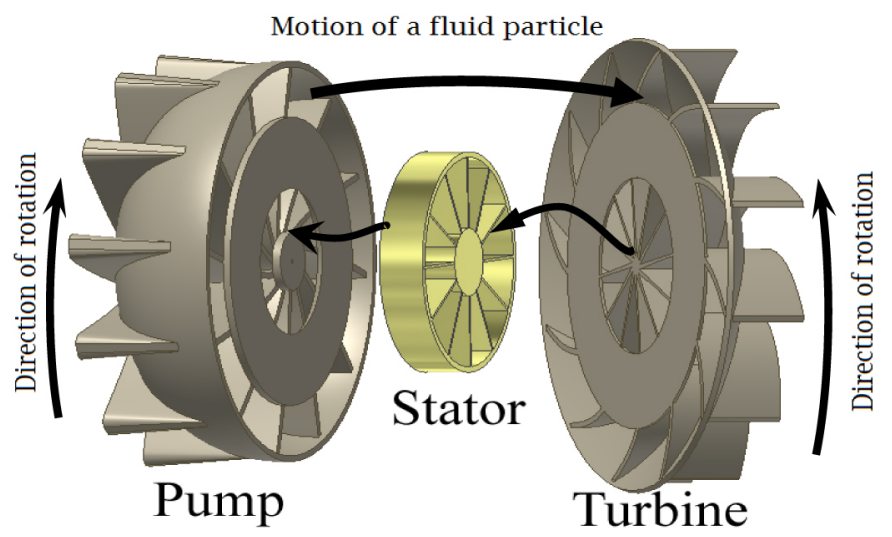

Figure 2. Schematic diagram of the motion of a fluid particle inside a torque converter

When the speed ratio is more than one, the torque converter works in the reverse flow mode. In this mode of operation the flow reverses, the stator overruns, and the turbine drives the pump. The reverse flow mode corresponds to the operation of engine braking.

The equations presented in this paper correspond to the forward mode of operation. In forward mode the elements that contribute to the energy of the system are the pump, the turbine, the stator and the hydraulic fluid. Since there are four components contributing to the energy of the system, there are four differential variables leading to four differential equations.

The torque balance formulation leads to the first three differential equations (

$$
\begin{aligned}
& I_{p} \dot{\omega}_{p}+\rho S_{p} \dot{Q}= \\
& \rho\left(-\omega_{p} R_{p}{ }^{2}-R_{p} \frac{Q}{A} \tan \alpha_{p}+\omega_{s} R_{s}^{2}+R_{s} \frac{Q}{A} \tan \alpha_{s}\right) Q-T_{p}
\end{aligned}
$$

$$
\begin{aligned}
& I_{t} \dot{\omega}_{t}+\rho S_{t} \dot{Q}= \\
& \rho\left(-\omega_{t} R_{t}^{2}-R_{t} \frac{Q}{A} \tan \alpha_{t}+\omega_{p} R_{p}{ }^{2}+R_{p} \frac{Q}{A} \tan \alpha_{p}\right) Q-T_{t}
\end{aligned}
$$

$$
\begin{aligned}
& I_{s} \dot{\omega}_{s}+\rho S_{s} \dot{Q}= \\
& \rho\left(-\omega_{s} R_{s}^{2}-R_{s} \frac{Q}{A} \tan \alpha_{s}+\omega_{t} R_{t}^{2}+R_{t} \frac{Q}{A} \tan \alpha_{t}\right) Q-T_{s}
\end{aligned}
$$


The fourth equation corresponds to the balance of energy for the system.

$\rho\left(S_{p} \dot{\omega}_{p}^{2}+S_{t} \dot{\omega}_{t}^{2}+S_{s} \dot{\omega}_{s}^{2}\right)+\frac{\rho L_{f}}{A} \dot{Q}=$

$\rho\left(R_{p}^{2} \omega_{p}^{2}+R_{t}^{2} \omega_{t}^{2}+R_{s}^{2} \omega_{s}^{2}-R_{s}^{2} \omega_{p} \omega_{s}-R_{p}^{2} \omega_{t} \omega_{p}-R_{t}^{2} \omega_{s} \omega_{t}\right)$

$+\omega_{p} \frac{Q}{A} \rho\left(R_{p} \tan \alpha_{p}-R_{s} \tan \alpha_{s}\right)$

$+\omega_{t} \frac{Q}{A} \rho\left(R_{t} \tan \alpha_{t}-R_{p} \tan \alpha_{p}\right)$

$+\omega_{s} \frac{Q}{A} \rho\left(R_{s} \tan \alpha_{s}-R_{t} \tan \alpha_{t}\right)-\frac{P_{s h}+P_{f}}{Q}$

In the above equations $\omega_{p}, \omega_{t}, \omega_{s}$ and $Q$ are the state variables. The first three state variables represent the angular velocities of the pump, turbine and the stator element and $Q$ represent the volumetric flow-rate of the hydraulic fluid in the system. A complete list of state variables and the parameters of the model are given in tables 1 and $\underline{2}$ respectively. Table 2 is presented in appendix A.

Table 1. State Variables

\begin{tabular}{|c|l|}
\hline Name & Description \\
\hline$Q$ & Flow rate of hydraulic fluid \\
\hline$\omega_{\mathrm{s}}$ & Angular speed of the stator \\
\hline$\omega_{\mathrm{p}}$ & Angular speed of the pump \\
\hline$\omega_{\mathrm{t}}$ & Angular speed of the turbine \\
\hline$\omega_{\mathrm{r}}$ & Speed Ratio \\
\hline$T_{\mathrm{r}}$ & Torque Ratio \\
\hline$\eta$ & Efficiency of the torque converter \\
\hline
\end{tabular}

The terms $P_{s h}$ and $P_{f}$ represent the losses due to shock and fluid friction respectively. They are expressed in terms of the fluid velocity and the geometry of the inner construction of the torque converter.

$$
\begin{gathered}
P_{s h}=\frac{\rho|Q| C_{s h}}{2}\left(\begin{array}{l}
\left(R_{s}\left(\omega_{s}-\omega_{p}\right)+\frac{Q}{A}\left(\tan \alpha_{s}-\tan \beta_{p}\right)\right)^{2} \\
+\left(R_{p}\left(\omega_{p}-\omega_{t}\right)+\frac{Q}{A}\left(\tan \alpha_{p}-\tan \beta_{t}\right)\right)^{2} \\
+\left(R_{t}\left(\omega_{t}-\omega_{s}\right)+\frac{Q}{A}\left(\tan \alpha_{t}-\tan \beta_{s}\right)\right)^{2}
\end{array}\right) \\
P_{f}=\frac{\rho|Q| C_{f} Q^{2}}{2 A^{2}}\left(3+\left(\tan \alpha_{p}\right)^{2}+\left(\tan \alpha_{t}\right)^{2}+\left(\tan \alpha_{s}\right)^{2}\right)
\end{gathered}
$$

In equation (5), $C_{s h}$ and $C_{f}$ are the shock and friction loss factors and are constants. The angles $\alpha$ and $\beta$ represent the exit and entry angles of the vanes. The subscripts s, $p$ and $t$ are used to denote the stator, pump and the turbine respectively.

We also define a few related quantities to help us represent the dynamics of the system. Speed ratio is the ratio of the angular speed of the turbine to that of the pump. For forward mode of operation this quantity is always less than unity.

$$
\omega_{r}=\omega_{t} / \omega_{p}
$$

Torque ratio is the ratio of the turbine torque to the pump torque.

$$
T_{r}=\left|T_{t} / T_{p}\right|
$$

In the forward mode of operation before the coupling occurs, the torque at the turbine is greater than that acting on the pump. Thus at this stage the torque ratio stays more than unity and corresponds to the phenomenon of torque multiplication. When the system reaches the coupling point, the torque ratio becomes close to unity and the pump and turbine torques become approximately equal to one another.

Efficiency is the ratio between the output power and the input power of the torque converter. It is expressed in terms of the torque and angular velocities of the pump and the turbine.

$$
\eta=\left|\left(T_{t} \omega_{t}\right) /\left(T_{p} \omega_{p}\right)\right|
$$

We also evaluate the capacity factor defined by the following expression.

$$
K_{c}=\omega_{p} / \sqrt{T_{p}}
$$

The capacity factor is a measure of the ability of the torque converter to absorb and transmit torque, Wong 7. During the operation of the torque converter, the capacity factor reaches its minimum value at stall conditions and increases with an increase of the speed ratio. For proper matching, the capacity factors of the torque converter and the engine should have similar ranges of values.

In the forward mode of operation, when the speed ratio is considerably less than unity, the one-way clutch holds the stator in place and prevents it from rotating. As a result, the quantity $\omega_{S}(t)$ is always zero at this stage. This reduces equation (3) to an algebraic equation and the total number of differential equations becomes three.

The stator torque required to hold the stator in place decreases as the turbine speed catches up with that of the 
pump. At the coupling point, when the stator torque becomes close to zero, the stator starts rotating. From this point onwards the system is governed by four differential equations, given by equations (1), (2), (3), (4).

\section{MODEL SIMULATION}

For this study we have specified the pump and the turbine torques, to correspond to the acceleration of the system. Figure 3 and Figure 4 show the pump and turbine torques used as inputs for this simulation. As a result of the specified torques, the angular speed of the turbine side, which is connected to the transmission, is expected to increase

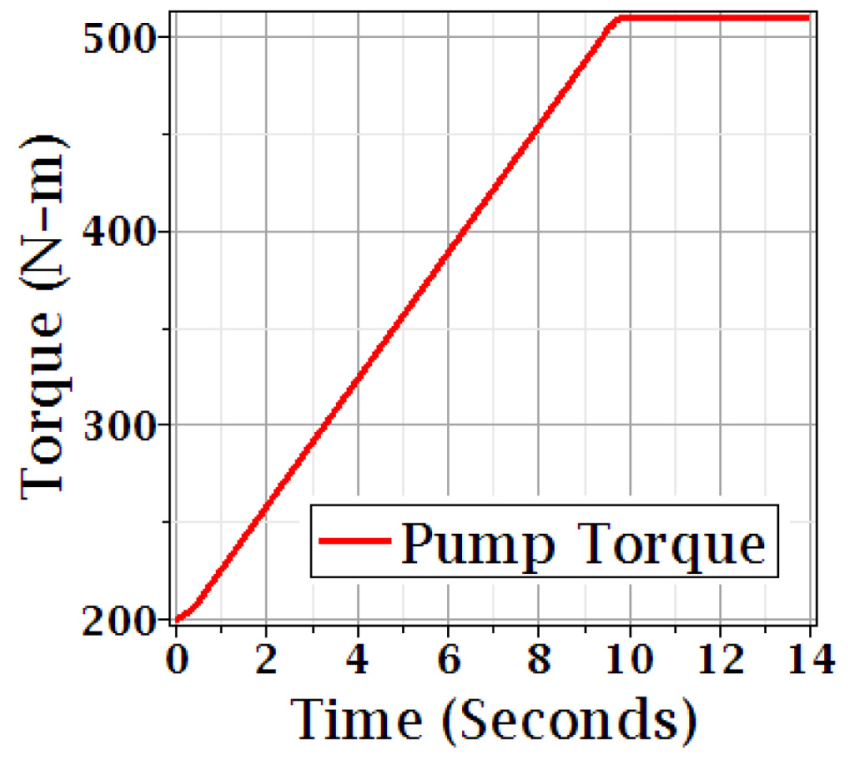

Figure 3. Specified pump torque

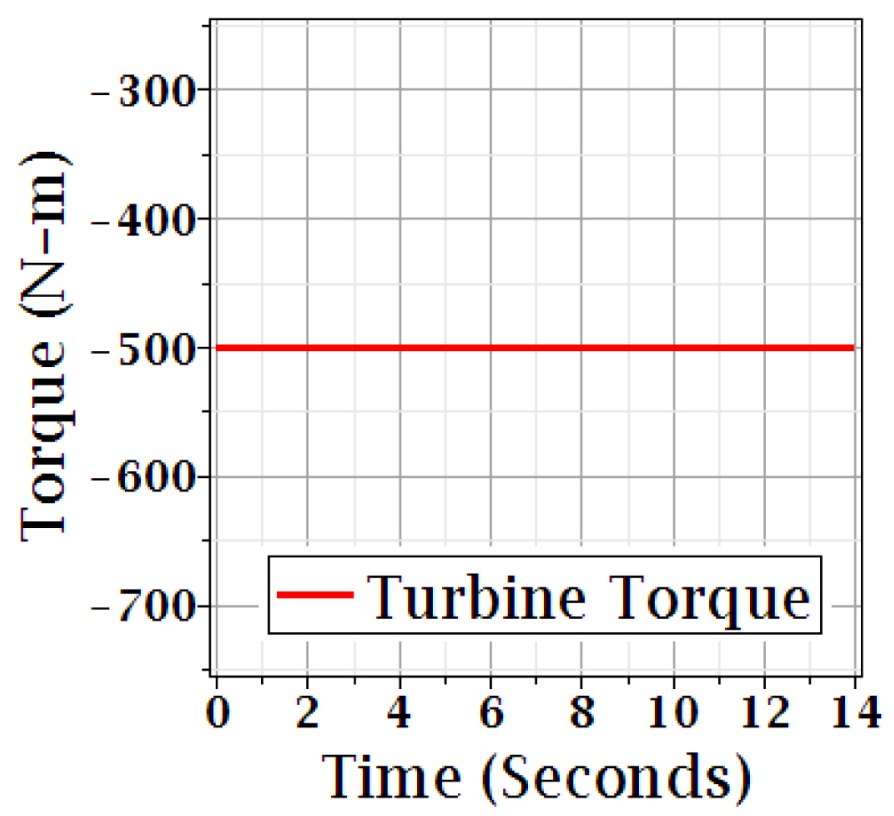

Figure 4. Specified turbine torque
To simulate the model, we have used Maple ${ }^{\mathrm{TM}}$, a powerful computational software package, as the working platform. Since there are two distinct stages of operation for the system, we simulate one stage at a time. We start the simulation by using the initial conditions shown in Table 3 . At this point the system is governed by three differential equations. The stator torque is calculated using equation (3) with $\omega_{s}$ set to zero and is used to detect the point where the coupling takes place, which occurs when $T_{s}$ goes to zero.

At the coupling point the stator starts rotating and the stator torque becomes zero. To simulate operation above the coupling point, we consider all four differential equations (1), (2), (3), (4) and set $T_{s}$ to zero. Also the final values of the state variables in the first stage are used as the initial conditions for this stage.

For this study we start the simulation with speed ratio at zero and stop when the stator speed gets to $\omega_{S}=20 \mathrm{rad} / \mathrm{s}$. The assumption is that at this point the lock-up clutch becomes activated and locks the relative angular velocity of the two sides of the torque converter and transforms it into a mechanical transmission. The reasons behind this particular choice of $\omega_{s}$, at which the lock-up clutch becomes activated, will be presented in a subsequent chapter.

Table 3. Initial conditions for the system

\begin{tabular}{|c|c|c|}
\hline States & Initial Values & Unit \\
\hline$Q(0)$ & 0.13 & $\mathrm{~m}^{3} / \mathrm{s}$ \\
\hline$\omega_{s}(0)$ & 0 & $\mathrm{rad} / \mathrm{s}$ \\
\hline$\omega_{p}(0)$ & 280 & $\mathrm{rad} / \mathrm{s}$ \\
\hline$\omega_{t}(0)$ & 0 & $\mathrm{rad} / \mathrm{s}$ \\
\hline
\end{tabular}

\section{SENSITIVITY EQUATIONS}

In this study we have used direct differentiation (Serban and Freeman 4) to generate the sensitivity equations. For systems governed by a set of non-linear $1^{\text {st }}$ order differential equations the equations can be written in matrix notation as

$$
\mathbf{M} \dot{\mathbf{q}}=\mathbf{F}
$$

For this system, $\mathbf{q}=\left[\omega_{p} \omega_{t} \omega_{s} Q\right]^{\mathrm{T}}$, the mass matrix $\mathbf{M}$ is a matrix $4 \times 4$ matrix and the force vector $\mathbf{F}$ is a $4 \times 1$ matrix. Starting with the assumption that the mass matrix $M$ and the force vector $\mathbf{F}$ are functions of time t, the state vector $\mathbf{q}$ and a set of model parameters represented by $\mathbf{p}$, we can write equation (10) as

$$
\mathbf{M}(\mathbf{q}, \mathbf{p}, \mathrm{t}) \dot{\mathbf{q}}(\mathbf{p}, \mathrm{t})=\mathbf{F}(\mathbf{q}, \mathbf{p}, \mathrm{t})
$$


Differentiating equation (11) with respect to a single parameter $\mathrm{b}$, where $\mathrm{b} \varepsilon p$, we get

$$
\begin{aligned}
& \left(\mathbf{M}_{\mathrm{b}}+\mathbf{P}\right) \dot{\mathbf{q}}+\mathbf{M} \dot{\mathbf{q}}_{\mathrm{b}}=\mathbf{F}_{\mathrm{b}}+\mathbf{F}_{\mathrm{q}} \mathbf{q}_{\mathrm{b}} \\
& \text { where } \mathbf{P}_{\mathrm{ij}}=\sum_{\mathrm{k}=1}^{\mathrm{n}} \frac{\partial \mathrm{m}_{\mathrm{ij}}}{\partial \mathbf{q}_{\mathrm{k}}}\left(\mathbf{q}_{\mathrm{k}}\right)_{\mathrm{b}}
\end{aligned}
$$

By combining equation (12) with equation (11) we form the equation:

$$
\left[\begin{array}{cc}
\mathbf{M}_{\mathrm{b}}^{4 \times 4}+\mathbf{P}^{4 \times 4} & \mathbf{M}^{4 \times 4} \\
\mathbf{M}^{4 \times 4} & 0^{4 \times 4}
\end{array}\right]\left\{\begin{array}{c}
\dot{\mathbf{q}}^{4 \times 1} \\
\dot{\mathbf{q}}_{\mathrm{b}}^{4 \times 1}
\end{array}\right\}=\left\{\begin{array}{c}
\mathbf{F}_{\mathrm{b}}+\mathbf{F}_{\mathbf{q}} \mathbf{q}_{\mathrm{b}} \\
\mathbf{F}
\end{array}\right\}^{8 \times 1}
$$

By numerically solving equation (13) the state variables of the system and the corresponding sensitivities can be calculated as functions of time. Further details of the solution procedure are provided in the subsequent sections. The expressions of the combined set of equations are presented in appendix B.

\section{IMPORTANCE ANALYSIS}

The model parameters, i.e. the dimensions and the geometric properties of the components and the physical and hydrodynamic properties of the hydraulic fluid, play a major role in determining the dynamics of a torque converter. For various analyses it is important to understand which of these parameters have more influence on the dynamics than others. In other words it is necessary to determine which of the parameters are most important for the model. Using sensitivity analysis it is possible to develop a relative order of importance among the parameters.

\section{OBJECTIVE FUNCTION}

To perform importance analysis on a system, we need to specify the criterion with respect to which the effects of the parameters would be measured and compared. The result of an importance analysis is very much dependent on this criterion or what is known as the objective function. A general objective function can be expressed in terms of the set of model parameters $\mathbf{p}$ and the state variables $\mathbf{q}$ and can be written in the general form:

$$
\lambda=\int_{\tau_{1}}^{\tau_{2}} f(\mathbf{q}, \mathbf{p}, \mathrm{t}) d t
$$

By differentiating equation (14) with respect to a single model parameter $b$, we obtain

$$
\lambda_{b}=\frac{\partial \lambda}{\partial b}=f\left(\mathbf{p}, \tau_{2}\right) \frac{\partial \tau_{2}}{\partial b}-f\left(\mathbf{p}, \tau_{1}\right) \frac{\partial \tau_{1}}{\partial b}+\int_{\tau_{1}}^{\tau_{2}}\left(\frac{\partial \mathrm{f}}{\partial \mathrm{b}}+\frac{\partial \mathrm{f}}{\partial \mathbf{q}} \mathbf{q}_{\mathrm{b}}\right) d t
$$

In the above equation, $\lambda_{b}$ is the sensitivity of the objective function with respect to an arbitrary model parameter $b$. It is also known as the absolute sensitivity of the objective function $\mathrm{f}$ with respect to the parameter. The quantity $\mathbf{q}_{\mathrm{b}}$ is the sensitivity of the state variables $\mathbf{q}$ with respect to the parameter $b$. These quantities are obtained by solving the set of differential equations in eq.(13).

The first two terms of equation (15) are required only if the limits of integrations are dependent on the parameter in question. Since for most of the time, the limits are independent of the model parameters, these terms don't figure in the expressions. However, for certain situations these assumptions might not be practical and due consideration must be given to these terms to ensure accurate computation of the sensitivity information.

Depending on the effect that a particular parameter has on the objective function, the value of the absolute sensitivity would be different and this piece of information can be used to arrange the parameters in their order of importance.

For this study, we have chosen the total loss of energy as the objective function for the importance analysis. The energy lost during the process can be written in terms of the input torque $T_{p}$, the angular velocity $\omega_{p}$ and the efficiency of the torque converter $\eta$ as

$$
\begin{gathered}
E_{\text {loss }}=\int_{0}^{\tau_{\text {lockup }}} \operatorname{Power}(t) d t \\
\operatorname{Power}(t)=T_{p}(t) \omega_{p}(t)(1-\eta(t))
\end{gathered}
$$

The upper limit of the integration $\tau_{\text {lockup }}$ is the time when the lock-up clutch joins the two sides of the torque converter into a single piece and eliminates the dynamic effects of the torque converter. Using (15) we can obtain the expression of the sensitivity of the quantity $E_{\text {loss }}$ with respect to an arbitrary model parameter as

$$
\begin{aligned}
& E_{\text {loss }_{b}}=\frac{\partial E_{\text {loss }}}{\partial b}=\operatorname{Power}\left(\tau_{\text {lockup }}\right) \times \frac{\partial \tau_{\text {lockup }}}{\partial b} \\
& +\int_{0}^{\tau_{\text {lockup }}}\left(\frac{\partial T_{p}}{\partial b} \omega_{p}(1-\eta)+T_{p} \frac{\partial \omega_{p}}{\partial b}(1-\eta)-T_{p} \omega_{p} \frac{\partial \eta}{\partial b}\right) d t
\end{aligned}
$$

The first term of equation (17) is particularly troublesome due to the fact that although the time of lock-up ( $\left.\tau_{\text {lockup }}\right)$ is dependent on the model parameters, it is not easily expressed as an explicit function of any of them. It is dependent on the termination criterion mentioned in the last section and is only determined from the numerical simulation.

Thus the only way to calculate the term $\frac{\partial \tau_{\text {lockup }}}{\partial b}$ is to approximate the derivative with a finite difference approach 
and simulate the model repeatedly with perturbed values of the parameter, something that may undermine the benefits of the direct differentiation approach. However, numerical comparison shows that the magnitude of this term is small compared to that of the second term and can be safely ignored for the purpose of analysis. Results confirming this statement are presented in a subsequent section.

\section{NORMALIZATION}

The absolute sensitivity of the objective function with respect to an arbitrary model parameter is a measure of the change in the objective function for a unit change in the parameter value, assuming a first order approximation. However this piece of information, in this form, is not very suitable to determine which parameter has more effect on the objective function. Since different parameters have different units, the significance of the perturbation of one unit is completely different for two separate parameters. To overcome this problem we normalize the absolute sensitivity by multiplying it with the nominal value of the parameter and dividing it by the nominal value of the objective function. This gives us what is known as the relative sensitivity of the objective function and is defined as (Smith et al. 5)

$$
\mu=\frac{\partial \mathrm{E}_{\text {loss }}}{\partial \mathrm{b}}\left|\frac{\mathrm{b}^{*}}{\mathrm{E}_{\text {loss }}\left(\mathrm{b}^{*}\right)}\right|
$$

In equation (18) the symbol $\mathrm{b}^{*}$ denotes the nominal value of the parameter. The quantity thus obtained, i.e. the normalized sensitivity $\mu$, represents the fractional change in the objective function for a fractional change in the value of the parameter. It is dimensionless and suitable for the purpose of comparison.

It is to be noted that while performing the normalization, it is important that absolute values are used, to ensure that the sense of direction of the changes are preserved in the relative sensitivity information.

\section{DESIGN OPTIMIZATION}

Using the sensitivity information a design optimization problem is set up to tune the model parameters of the torque converter for a better design. To improve the design of the torque converter, the main criterion is to minimize the energy loss during the operation, however, it is also a general observation that when efficiency is increased the torque capacity of a torque converter usually goes down. As a result, a more efficient torque converter often becomes severely restricted in terms of usability. Therefore, the proper optimization philosophy should focus on decreasing the area under the power lost curve and increasing the area under the torque capacity curve, at the same time. To achieve that, we combine the two separate criteria into a single objective function using the expression given below.

$$
\begin{gathered}
\lambda=\frac{a_{1}}{T_{p}(0) \omega_{p}(0)}\left(\int_{0}^{\tau_{\text {coupling }}} T_{p}(t) \omega_{p}(t)(1-\eta(t)) d t\right) \\
-\frac{a_{2}}{K_{c}(0)}\left(\int_{0}^{\tau_{\text {coupling }}} K_{c}(t) d t\right)
\end{gathered}
$$

In equation (19), the two integrals represent the two separate criteria that are being combined into a single objective function. Since the equation features quantities with different units and physical significance, reference values of the relevant quantities are used to make the objective function non-dimensional. The constants $a_{1}$ and $a_{2}$ are the weight coefficients that determine the relative importance given to the individual criterion. It is to be noted that the outcome of the optimization is expected to be strongly dependent on the values of these weights.

By using direct differentiation and assuming minimal dependence of the term $\tau_{\text {coupling }}$ on the model parameters, as discussed in the previous section, we obtain the expression for the sensitivity of the objective function. This expression is to be used to determine the sensitivity of the objective function during the optimization iterations.

$$
\begin{aligned}
& \frac{\partial \lambda}{\partial \mathrm{b}} \approx \frac{\mathrm{a}_{1}}{\mathrm{~T}_{\mathrm{p}}(0) \omega_{\mathrm{p}}(0)} \int_{0}^{\tau_{\text {lockup }}} \Gamma \mathrm{dt}-\frac{\mathrm{a}_{2}}{\mathrm{~K}_{\mathrm{c}}(0)} \int_{0}^{\tau_{\text {lockup }}} \frac{\partial \mathrm{K}_{\mathrm{c}}}{\partial \mathrm{b}} \mathrm{dt} \\
& \Gamma=\left(\frac{\partial \mathrm{T}_{\mathrm{p}}}{\partial \mathrm{b}} \omega_{\mathrm{p}}(1-\eta)+\mathrm{T}_{\mathrm{p}} \frac{\partial \omega_{\mathrm{p}}}{\partial \mathrm{b}}(1-\eta)-\mathrm{T}_{\mathrm{p}} \omega_{\mathrm{p}} \frac{\partial \eta}{\partial \mathrm{b}}\right)
\end{aligned}
$$

In this study we want to give equal importance to the two aspects of optimization. The individual parts of the objective function are rendered non-dimensional by dividing them by their initial values. During the simulation these nondimensional components vary within different ranges. The values of $a_{1}$ and $a_{2}$ are chosen to scale these ranges and make them comparable to one another. Also for proper scaling, it is important to ensure that $a_{1}+a_{2}=1$. Using the ranges for the components of the objective function for the original system, the weights were determined to be

$$
a_{1}=0.47 \text { and } a_{2}=0.53
$$

Importance analysis reveals the list of model parameters which have more influence on the performance of the torque converter than others. For the purpose of the design optimization we choose the most important parameters and consider other parameters to be constants, since they are not expected to have a great influence on the objective function.

We have used gradient-based steepest decent method to adjust the parameters. The parameter values were restricted to 
be inside a particular range that is considered to be practical. Details about the setup of the optimization problem and the results obtained thereof are presented in the next section.

\section{RESULTS}

Using the inputs shown in Figure 3 and Figure 4 the combined equations shown in (13) are solved numerically in Maple ${ }^{\mathrm{TM}}$, using built in solver "dsolve[numeric]". The "rkf45_dae" option was used for the simulation which uses "Fehlberg fourth-fifth order Runge-Kutta method" to solve differential algebraic equations. The maximum function evaluation was set at maxfun $=100000$ with default error tolerance at $\varepsilon=10^{-6}$.

Figure 5 shows the variation of the pump speed $\omega_{p}$ and the turbine speed $\omega_{t}$ as the speed ratio increases during the simulation. To obtain this plot the simulation was allowed to run until the speed ratio reached $\omega_{r}=0.8$. The difference between the pump speed and the turbine speed is also plotted on the same axes.

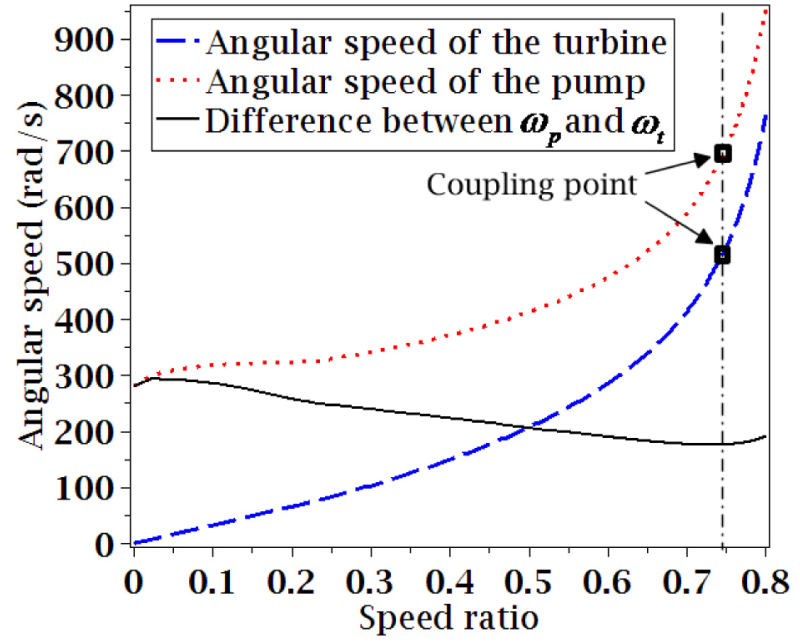

Figure 5. variation of $\omega_{p}$ and $\omega_{t}$ with the change in the speed ratio

The pump speed is found to increase from the initial 280 $\mathrm{rad} / \mathrm{s}$ and is associated with the increased torque coming from the engine. As the pump speed increases, because of fluid coupling, the turbine speeds up from its initial stationary state and eventually the system reaches the coupling point when the stator starts to rotate.

Usually the speed ratio is used to get a qualitative description of the difference between the angular speed of the turbine and that of the pump. However, this notion can be misleading at times. If we look at the differences between the pump speed and the turbine speed, we can find some interesting features. From Figure 5, it can be clearly noticed that before the coupling point, the difference between the turbine and pump speed decreases steadily. At this stage, increasing speed ratio is associated with the phenomenon of the turbine catching up with the pump. However, after the coupling point is reached, the difference between the pump speed and the turbine speed starts to increase. Contrary to the observed trend in the pre-coupling stage, a higher speed ratio at this stage actually represents the two speeds moving away from each other.

The increase in the difference between the pump speed and the turbine speed in the post-coupling phase can be explained by considering the dynamics of the system. Before the coupling point, the difference between the turbine speed and pump speed decrease due to fluid coupling. At this point the only components storing energy are the pump, the turbine and the hydraulic fluid. However after the coupling point is reached, the stator starts to rotate and stores some energy due to it angular motion. As the stator speeds up, more energy is channeled into the stator as its kinetic energy. This increases the difference between the pump speed and turbine speed.

With this observation we can explain the choice of the termination criterion as described in the previous section. To perform the locking operation, it is desirable that the turbine speed and the pump speed are as close to each other as possible. Since the difference between these speeds increase in the post-coupling stage, it is therefore logical to activate the lock-up clutch right after the coupling occurs. For this study the simulations were terminated when the stator speed reached $\omega_{S}=20 \mathrm{rad} / \mathrm{s}$.

Figure 6 shows the variation of the efficiency of the operation during the process. Figure 6 clearly shows the increase in efficiency during the initial phase of operation. As the speed ratio approaches the coupling point the efficiency falls and then it rises somewhat after the stator starts rotating.

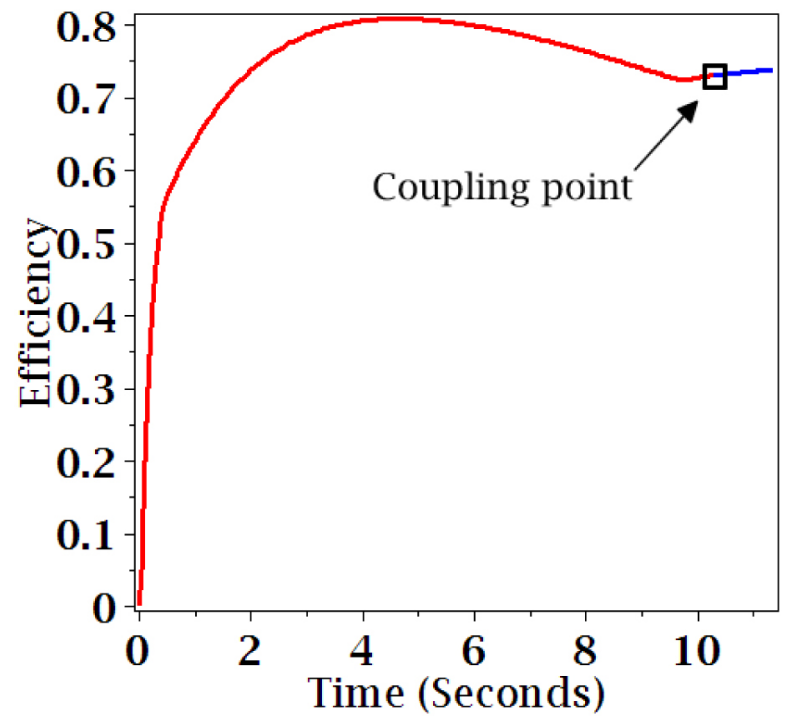

Figure 6. Variation of efficiency during the operation

Figure 7 shows the input and the output powers of the system. These quantities are obtained by multiplying the torque and the angular speed of the pump and the turbine respectively. The difference between the two curves, i.e. the difference between the input and output power, can be 
accounted for by adding the rate of change of energy stored in the torque converter elements and the losses incurred, given by equation (5), during the process.

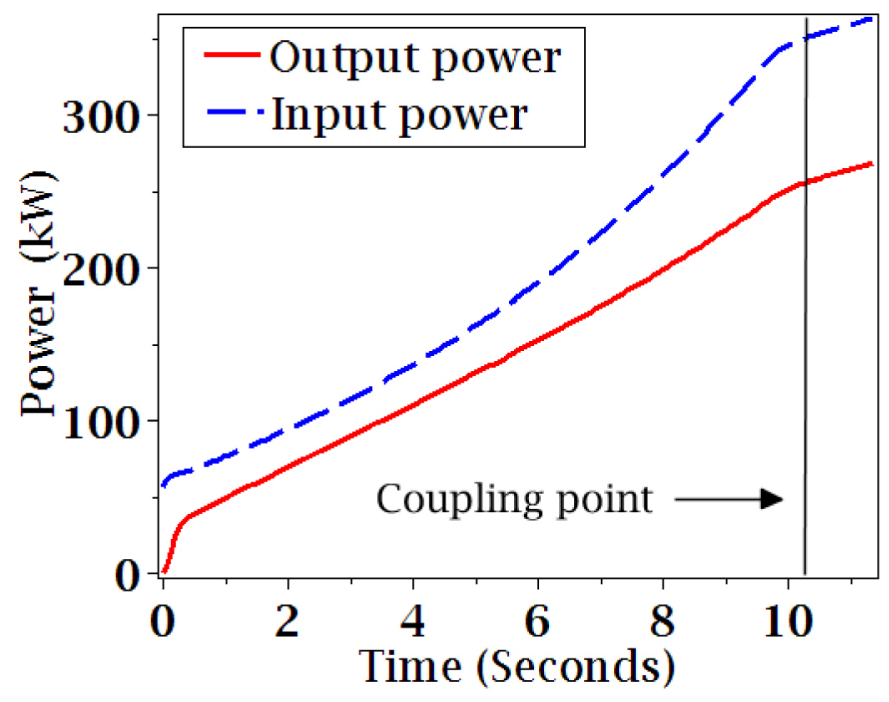

Figure 7. Input and output power of the system

Figure 8 shows the power lost due to shear stresses in the boundary layer (friction losses) and non-ideal flow conditions at the interfaces between the components (shock losses), during the operation of the torque converter. The total power lost during the process is also plotted on the same axes. This plot clearly shows that the total lost power hits a minimum at around $t=3$ seconds. As a result the difference between the input power and the output power goes through a minimum at around the same point. Also the efficiency stays high around this point, as shown in Figure 6, due to relatively low value for lost power.

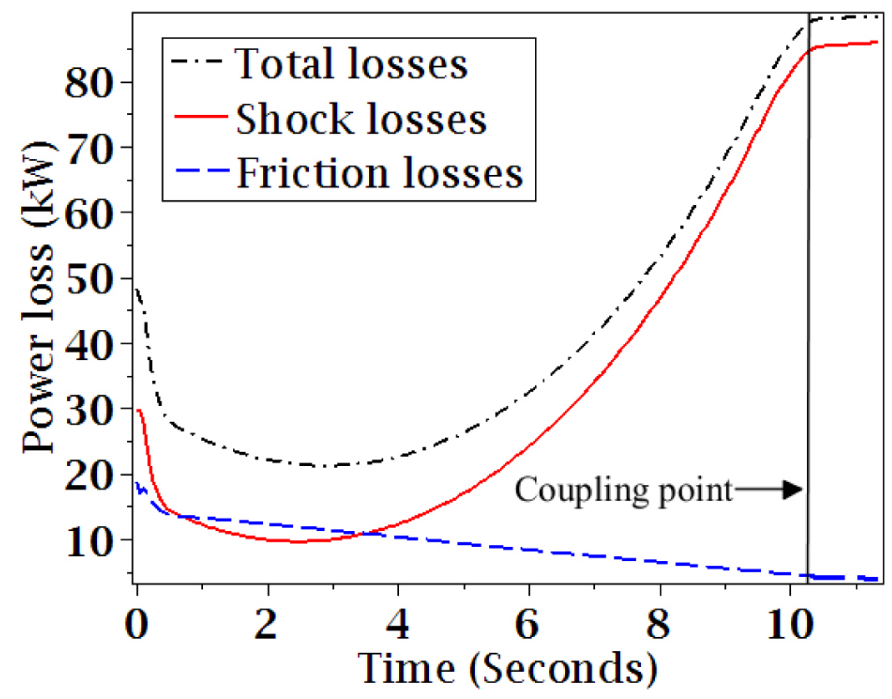

Figure 8. Losses due to shock effects and fluid friction
By comparing Figure 8 and Figure 6 , it can be explained why the efficiency decreases after going through a maximum. It is because, at that stage the losses increase, making the difference between the input and output power more pronounced.

Right before the coupling point and thereafter, the losses become more or less constant, as shown in Figure 8. This makes the input and output power curves almost parallel to each other (Figure 7). This results in a somewhat slow increase in the efficiency of the torque converter at this stage. Figure 8 also identifies the shock losses as the predominant form of power loss for the system.

\section{IMPORTANCE OF PARAMETERS}

The sensitivity of the objective function as outlined in (17) poses a question of whether or not the derivative of the lock-up time with respect to the model parameter is significant compared to the other terms in the expression. In a mathematical form it translates to the question of whether or not

$$
\xi=\int_{0}^{\mathrm{T}_{\text {lockup }}}\left(\frac{\partial \mathrm{T}_{\mathrm{p}}}{\partial \mathrm{b}} \omega_{\mathrm{p}}(1-\eta)+\mathrm{T}_{\mathrm{p}} \frac{\partial \omega_{\mathrm{p}}}{\partial \mathrm{b}}(1-\eta)-\mathrm{T}_{\mathrm{p}} \omega_{\mathrm{p}} \frac{\partial \eta}{\partial \mathrm{b}}\right) \mathrm{dt}
$$

is a good approximation for the sensitivity of the objective function $\mathrm{E}_{\text {loss }_{\mathrm{b}} \text {, as shown in eq. (17). }}$.

One possible way to resolve this issue is to compare the values obtained for the quantity $\xi$ by evaluating equation (22) and the evaluation of the quantity $\mathrm{E}_{\text {loss }_{\mathrm{b}}}$ using a finite difference formulation, which would require simulation of the system with appropriate perturbed values for the parameters.

To determine the correct perturbation factor for this system, we perform a convergence test where a parameter is perturbed by a series of small factors $\delta$ and the resulting perturbed values i.e. $b^{\tilde{}}=b^{*} \times(1 \pm \delta)$ are used to simulate the system and calculate the sensitivity of the objective function using a central difference formulation. We would expect the results to converge for an appropriate value of $\delta$. Furthermore if $\xi$ is a good approximation of the quantity $\mathrm{E}_{\text {loss }_{\mathrm{b}} \text {, we would }}$ expect that the finite difference results would agree with the results obtained by direct differentiation.

Figure 9 shows the result of one such study. The perturbation factor $\delta$ was varied from $10^{-2}$ to $10^{-8}$ and sensitivities were calculated using central difference formulation. It shows that the solution converges for perturbation factors between $10^{-3}$ and $10^{-6}$. Also it is to be noted that the convergence occurs close to the value calculated using direct differentiation, which is indicative of the accuracy of the approximation. 


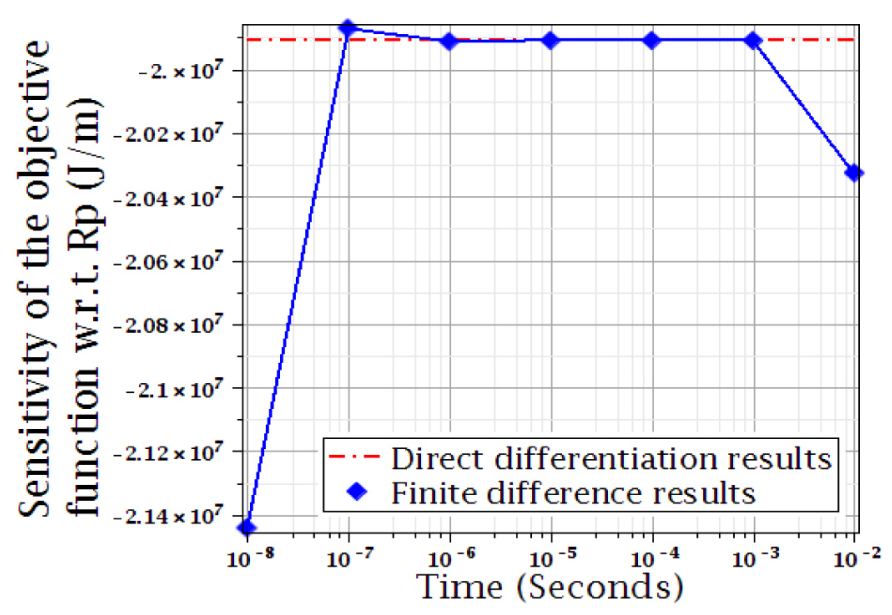

Figure 9. Convergence study to determine optimal perturbation factor

This difference between the results from the direct differentiation application and that from finite difference formulation are dependent on the values of the parameters. We have studied the error between the quantity $\xi$ and $\underline{\partial \tau_{\text {lockup }}}$

$\partial b$ for ranges of values of different parameters. The results are shown in Figure 10.

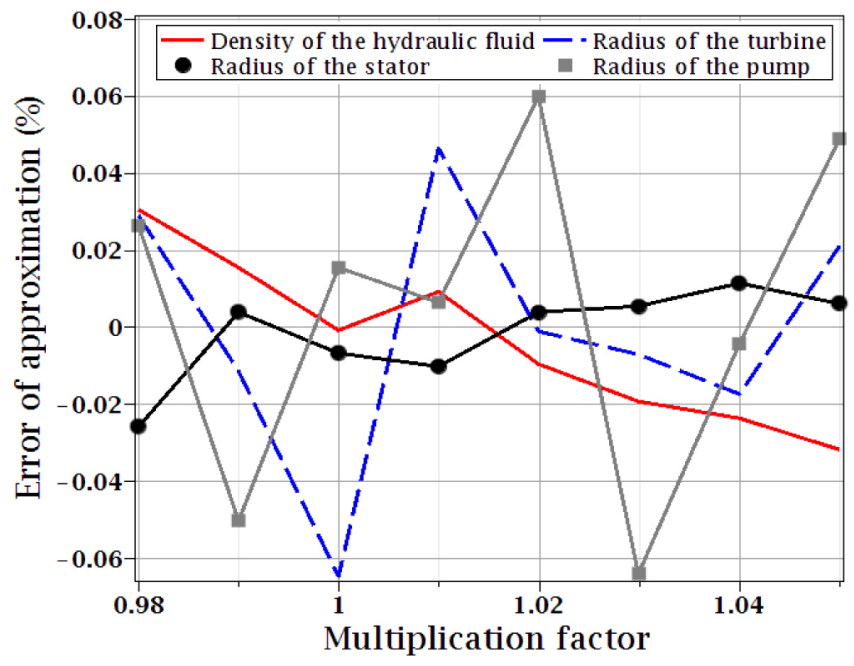

Figure 10. Error in approximation for different values of parameters.

In this plot, the percent error of approximation is plotted along the vertical axis and the normalized range of the parameter values are plotted on the horizontal axis. This way the horizontal axis represents the factor, which the nominal value of a particular parameter is multiplied with, to arrive at the new value of the parameter. The figure shows the trend for four different parameters.

From the above figures, it is quite clear that, for the relevant ranges of parameter values, the quantity $\xi$ is indeed a good approximation of the sensitivity of the objective function $\mathrm{E}_{\text {loss }_{\mathrm{b}} \text {. Therefore, we can safely neglect the leading }}$ term of eq.(17), and use eq. (22) to evaluate the sensitivity of the objective function, with respect to any arbitrary parameter, at least for the simulation considered.

Using eq. (18) and (22), we evaluate the relative sensitivity of the objective function, with respect to all the parameters. Table 4 shows the list in decreasing order of importance. It is to be noted that while arranging the parameters in this order, only the absolute value of the normalized sensitivity score is taken into consideration.

Table 4. Importance score for the model parameters

\begin{tabular}{|c|c|c|}
\hline Parameters & Absolute Sensitivity & $\begin{array}{c}\text { Normalized } \\
\text { Sensitivity score }\end{array}$ \\
\hline $\mathrm{R}_{\mathrm{p}}$ & $-1.99 \times 10^{7}$ & -4.11 \\
\hline $\mathrm{R}_{\mathrm{s}}$ & $1.85 \times 10^{7}$ & 2.91 \\
\hline$\alpha_{\mathrm{s}}$ & $1.47 \times 10^{4}$ & 1.71 \\
\hline $\boldsymbol{\rho}$ & $-3.62 \times 10^{2}$ & -0.55 \\
\hline $\mathbf{A}$ & $-3.03 \times 10^{7}$ & -0.55 \\
\hline $\mathrm{R}_{\mathrm{t}}$ & $-3.63 \times 10^{6}$ & -0.44 \\
\hline$\alpha_{\mathrm{t}}$ & $-3.25 \times 10^{3}$ & -0.34 \\
\hline $\mathrm{I}_{\mathrm{t}}$ & $9.11 \times 10^{4}$ & 0.05 \\
\hline $\mathrm{I}_{\mathrm{p}}$ & $8.68 \times 10^{4}$ & 0.01 \\
\hline$\alpha_{\mathrm{p}}$ & $-1.08 \times 10^{3}$ & 0 \\
\hline
\end{tabular}

Table 4 clearly identifies the radii of the pump, stator and turbine, the density of the hydraulic fluid, and the stator exit angle to be the most important parameters of the model from the stand point of the chosen objective function, i.e. total energy loss during the process. From this table, we can understand that, for a design optimization problem, these parameters should be given priorities, because they would have the greatest influence on the objective function.

At this point, it should be clarified that, while the magnitudes of the sensitivity information tell us the amount of influence a particular parameter has on the objective function, its sign tells us the direction in which this influence acts. This piece of information is critical for design optimization problems, where the direction of steepest descent is required, to arrive at the optimal point. Also it needs to be stated that, this result reflects the behavior of the system in a strictly local sense and is therefore restricted to be valid for small perturbations only. To validate the sensitivity information, obtained using the analysis shown above, and to illustrate the effect of the perturbation size on the accuracy of the computation, we compare the amount of lost energy for a 
perturbed system with that predicted by an approximation, based on first order sensitivity analysis of the original system.

The approximation can be written as or

$$
{ }^{*} E_{\text {loss }}=E_{\text {loss }}+E_{\text {loss }} \delta b
$$

In the above expression ${ }^{*} E_{\text {loss }}$ is the predicted loss of energy for the perturbed system, $E_{\text {loss }}$ and $\mathrm{E}_{\text {loss }_{\mathrm{b}} \text { correspond }}$ to the original system and $\delta b$ denotes the perturbation of the parameter.

The difference between the quantities $* E_{\text {loss }}$ and the loss calculated by simulating the perturbed system can be used to assess the accuracy of the sensitivity analysis for different perturbation sizes. The results of the comparison are shown in Figure 11.

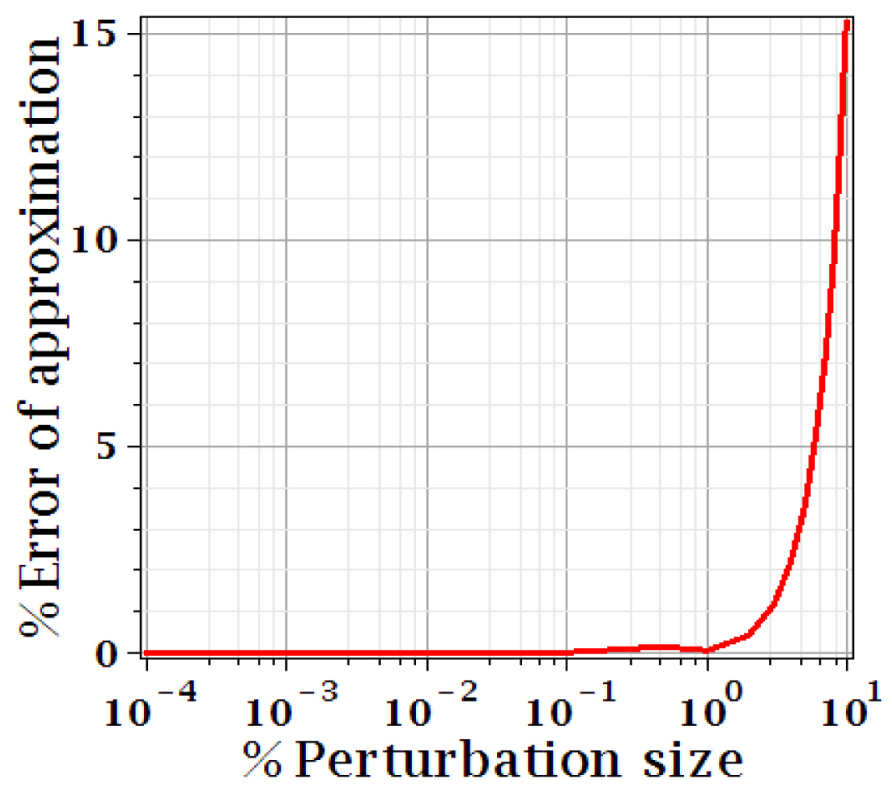

Figure 11. Accuracy of the sensitivity analysis for different perturbation sizes of $R p$

In the above figure the percentage perturbation of the parameter $R_{p}$ was plotted on the horizontal axis using a $\log$ scale. The percentage difference between the values calculated using eq. (23) for the original system and eq. (16) for the perturbed system are plotted on the vertical axis. This plot clearly shows the dependence of the accuracy of sensitivity analysis on the perturbation size and it also validates the sensitivity results with respect to the parameter $R_{p}$ for small perturbations. Similar verifications can be done for the other parameters.

\section{DESIGN OPTIMIZATION}

A design optimization problem is setup to determine the optimal values for the physical parameters of the model. Since results from the importance analysis identify the radii of the components to be the most influential parameters, we choose the parameters $R_{p}, R_{s}, R_{t}$ and $\rho$ for optimization. The problem statement along with the imposed constrains are given below.

Find $R_{p}, R_{s}, R_{t}$ and $\rho$ that would

$$
\begin{aligned}
\operatorname{minimize} \lambda= & \frac{0.47}{T_{p}(0) \omega_{p}(0)}\left(\int_{0}^{\tau_{\text {coupling }}} T_{p}(t) \omega_{p}(t)(1-\eta(t)) d t\right) \\
& -\frac{0.53 \sqrt{T_{p}(0)}}{\omega_{p}(0)}\left(\int_{0}^{\tau_{\text {coupling }}} K_{c}(t) d t\right)
\end{aligned}
$$

$$
\begin{array}{cc}
0.100 \leq R_{p} \leq 0.13 \\
\text { Subjected to the following constraints } & 0.083 \leq R_{s} \leq 0.09 \\
0.065 \leq R_{t} \leq 0.13 \\
830 \leq \rho \leq 880
\end{array}
$$

Where $T_{p} \omega_{p}, \eta$ and $K_{\mathrm{c}}$ satisfy equations (1), (2), (3), (4), (5), (6), (7), (8), (9), $\tau_{\text {lockup }}$ is the time when the lock-up clutch gets activated, $T_{p}(0)$ is the input torque at $\mathrm{t}=0$ and $\omega_{p}(0)=280$ according to the initial condition, Table 3 .

\section{OPTIMIZED PARAMETER VALUES}

The optimization problem is solved by using the method of steepest descent. Equation $\underline{22}$ was used to determine the gradient information for the objective function. The values that are determined to be optimal for the specified problem and the corresponding loss of energy are

$$
\left[R_{t}=0.07 \quad R_{p}=0.12 \quad R_{s}=0.083 \quad \rho=830\right] \text { and } E_{\text {loss }}=395.47 \mathrm{~kJ}
$$

At this point it is worthwhile to take note of the initial values of the parameters of the system before optimization was performed and the corresponding loss of energy.

$\left[R_{t}=0.068 \quad R_{p}=0.115 \quad R_{s}=0.088 \quad \rho=840\right]$ and $E_{\text {loss }}=557.68 \mathrm{~kJ}$

The effects of the optimized model parameters are clearly evident in the behavior of the system. Figure 13 plots the efficiency of the system as a function of the speed ratio for the optimized and the original system. It shows a clear increase in the efficiency of operation right before the coupling point, an area where the efficiency usually drops down. Also the efficiency at the coupling point is found be improved. 


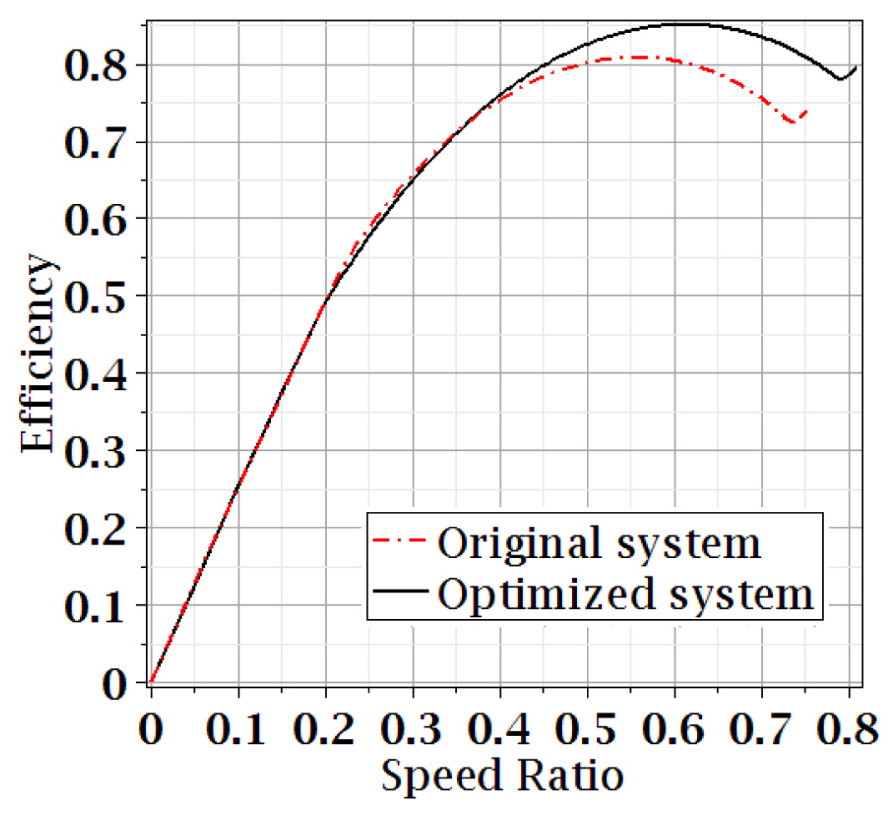

Figure 13. Efficiency of the system before and after the optimization

Apart from the improvement in the efficiency of the operation, the optimization also increases the speed ratio at which the lock up clutch is activated. To minimize the degradation of the components, the lock-up clutch is activated when the difference between the pump speed and the turbine speed is at its minimum. This happens near the coupling point as demonstrated in Figure 5 . Figure 14 shows the variation of the pump speed and the turbine speed for the optimized system. The difference between the two speeds is also plotted on the same axes.

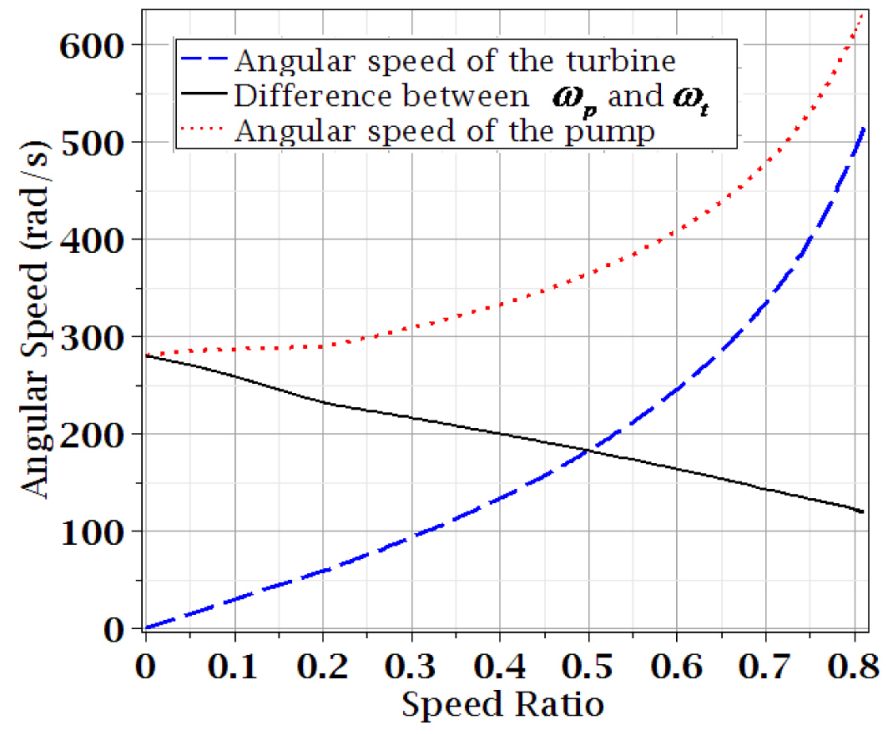

Figure 14. Angular speeds of pump and turbine for the optimized system
The figure clearly demonstrates that in the optimized system, when the lock-up clutch is activated, the difference between the angular speeds of the pump and turbine is around $125 \mathrm{rad} / \mathrm{s}$, which is lower than in the original system as shown in Figure 5.

The exact point when the lock-up clutch is activated is not an ironclad specification. For this system we have assumed that the lock-up clutch is activated when the stator speed $\omega_{\mathrm{S}}$, reaches $20 \mathrm{rad} / \mathrm{s}$. It was observed that the optimized system reaches this point somewhat earlier than the original system, as shown in Figure 15.

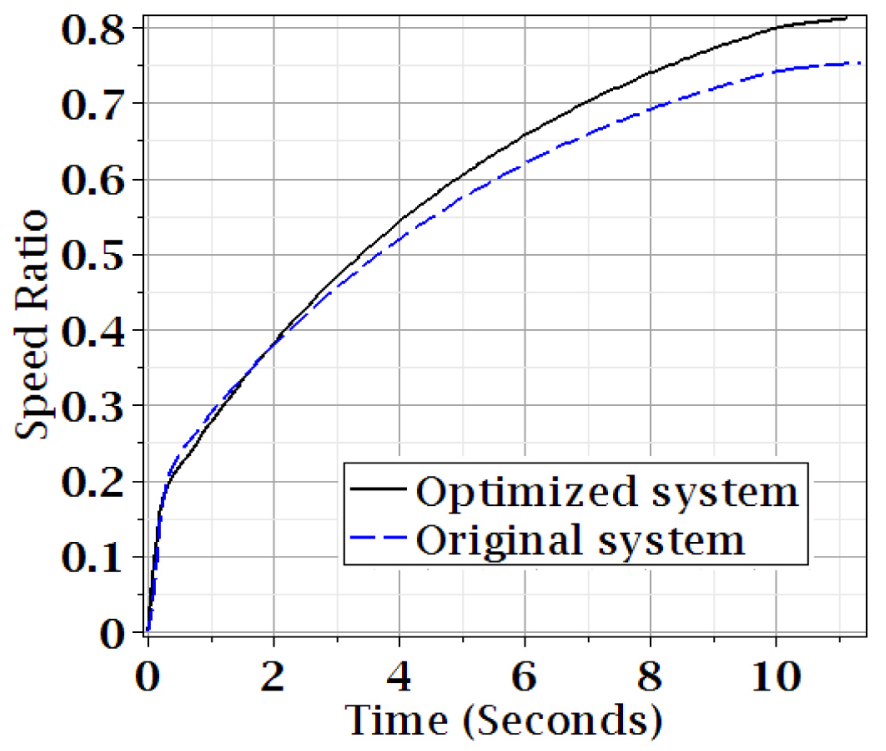

Figure 15. Speed ratio vs. time plot for the optimized and the original system

The combined effect of the decreased $\tau_{\text {lockup }}$ and improved efficiency can be clearly seen in Figure 16. In this figure the lost power is plotted on the vertical axis and time is plotted on the horizontal axis. The plot clearly shows that in the optimized system, the power loss is lower than that in case of the original system and the system runs for less time.

To understand the modality by which the optimized parameters minimize loss of energy, it is important to study different types of losses and the effect of the optimization on them. Shock losses and friction losses are the two types of losses included in this model. Shock losses are due to nonideal flow velocity conditions inside the torque converter and the friction losses are due to fluid friction and pressure drag effects. Figure 17 shows the variation of the friction losses with time for the optimized and original system. 


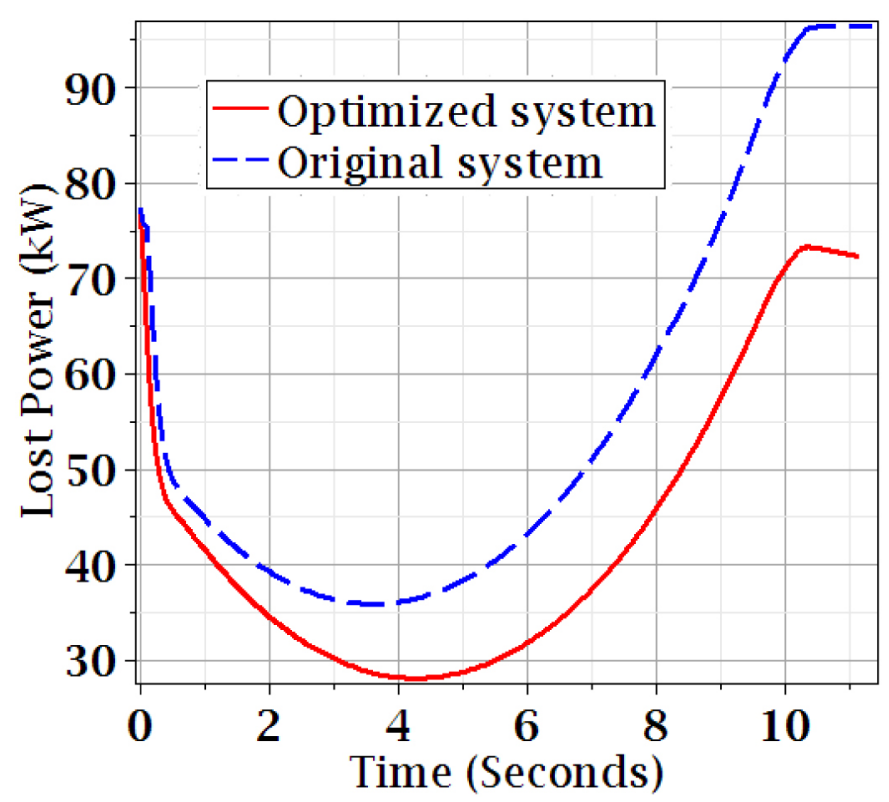

Figure 16. Lost power vs. time plot for the optimized and original system

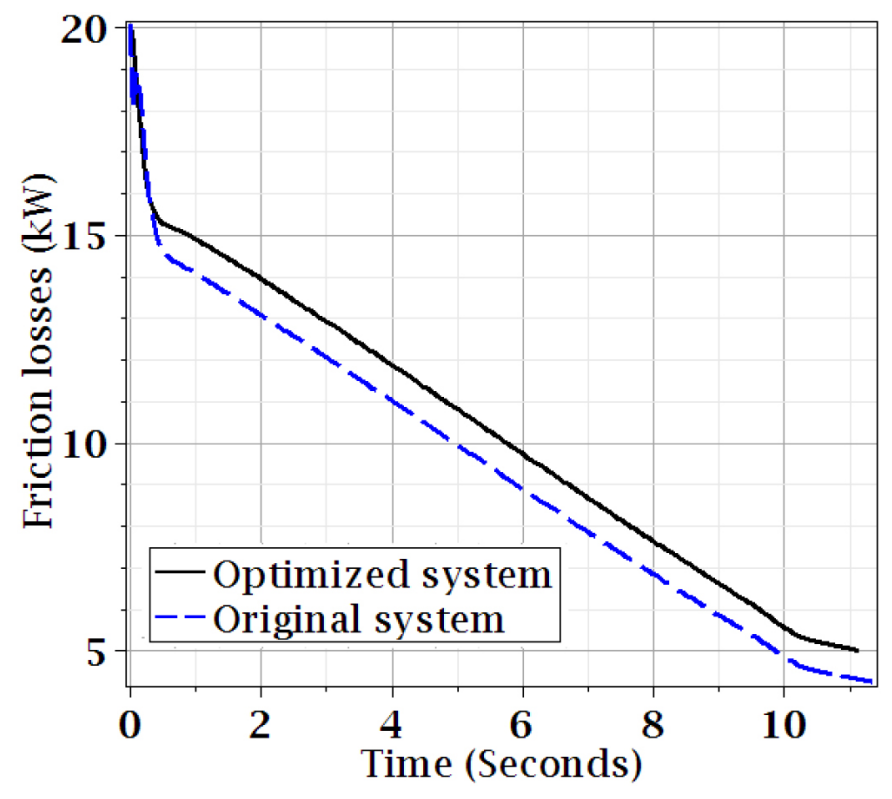

Figure 17. Friction losses vs. speed t ratio for the original and the optimized system

In Figure 18, the variation of the shock losses for the optimized and the original systems are plotted on the vertical axis and time in seconds is plotted on the horizontal axis.

The plots shown in Figure 17 and Figure 18 clearly show the effect of the optimized parameters on the individual loss terms. They once more establish the shock losses as the dominant loss term for the system and outline the reduction in power loss for the optimized system. It is also observed that in the optimized system the friction loss term is more than that in the original system. However, due to the fact that the shock losses are the predominant loss term and in the optimized system the shock losses are less than that in the original system, the total power loss in the optimized system is considerably lower than that in the original system, Figure 16 .

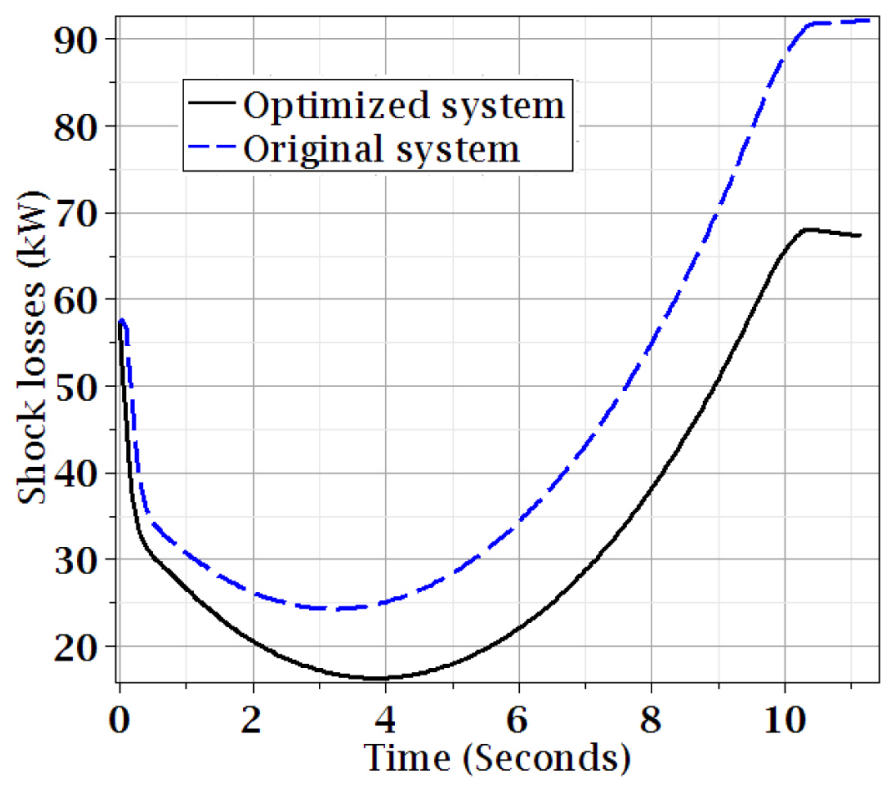

Figure 18. Shock losses vs. speed ratio for the original and the optimized system

To explain why the optimized system has lower shock loss term, we need to consider the angular velocity of the pump and the turbine, as shown in Figure 14. The plot clearly demonstrates that, in the optimized system, the final angular velocity of the pump and the turbine, right before the activation of the lock-up clutch, is lower than that in case of the original system. Since the shock losses are dependent on the angular speeds of the components of the torque converter, lower values of $\omega_{p}$ and $\omega_{t}$ result in lower shock losses for the system.

The optimized system requires less time to reach the locked up state, which results in higher volumetric flow rate of the hydraulic fluid. Since the friction losses are governed by equation (5), and are dependent on the flow rate of the fluid, a higher flow rate results in higher friction losses.

\section{EFFECT ON THE CAPACITY FACTOR}

As mentioned in a previous section, the variation of the capacity factor of the torque converter limits its usability in many situations. It is therefore worthwhile to investigate the behavior of the capacity factor for the optimized system. Figure 19 shows the variation of the capacity factor, for both original and the optimized system. It clearly shows that the range of variations of the capacity factor for the original and the optimized torque converter are comparable to each other, although it is a little tighter for the optimized system. 


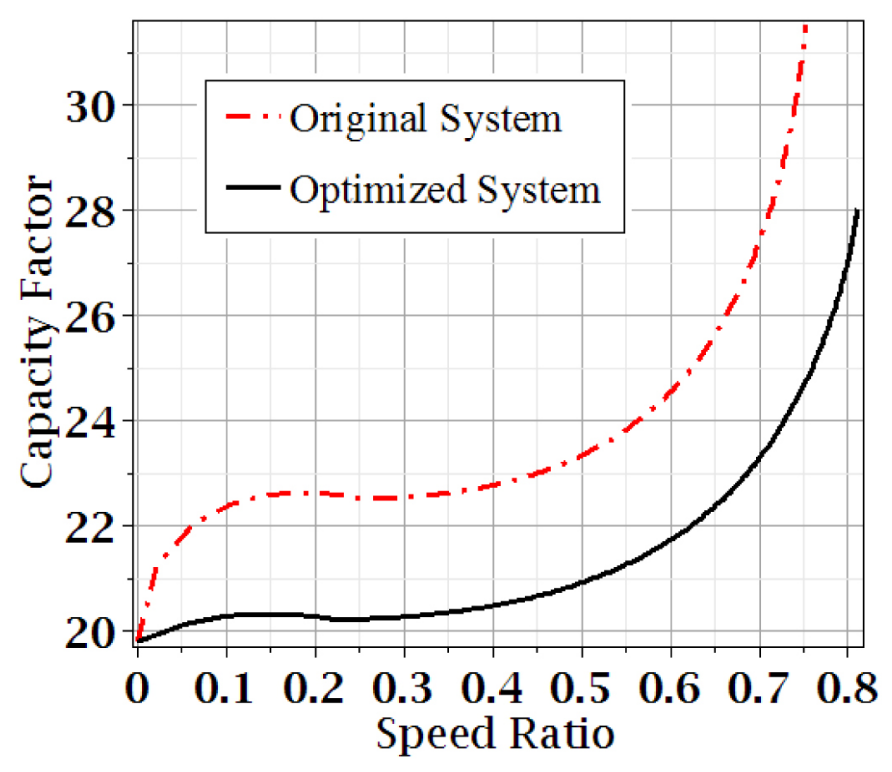

Figure 19. Capacity factor for the original and the optimized system

The merit of including the capacity factor into the objective function can be readily demonstrated by solving the optimization system with a different set of weights. To demonstrate this issue, we choose $\mathrm{a}_{1}$ to be unity and $\mathrm{a}_{2}$ to be zero. This choice of weights corresponds to the optimization philosophy where we completely disregard the capacity factor and solely concentrate on minimizing the energy losses during the operation. We solve the optimization problem, equation (19) subjected to the same constraints, equation (25) and obtain the following values for the optimized parameters.

$\left[R_{t}=0.093 \quad R_{p}=0.13 \quad R_{s}=0.083 \rho=880\right]$ and $E_{\text {loss }}=268.07 \mathrm{~kJ}$

Figure 20 shows the variation of the capacity factor for the original system and also the system that uses parameter values shown in equation (28).

The range of variation of the capacity factor in this case is found to be severely limited. We also notice that the energy loss for this particular system is lower than that of the system specified in equation (26).

At this point we can demonstrate the benefits of including the capacity factor into the objective function. From these results it can be clearly inferred that, if the objective function is solely focused on minimization of power losses, the result would be a more efficient but less usable system. Thus to ensure that the approach is practical the only way is to include the capacity factor into the optimization procedure.

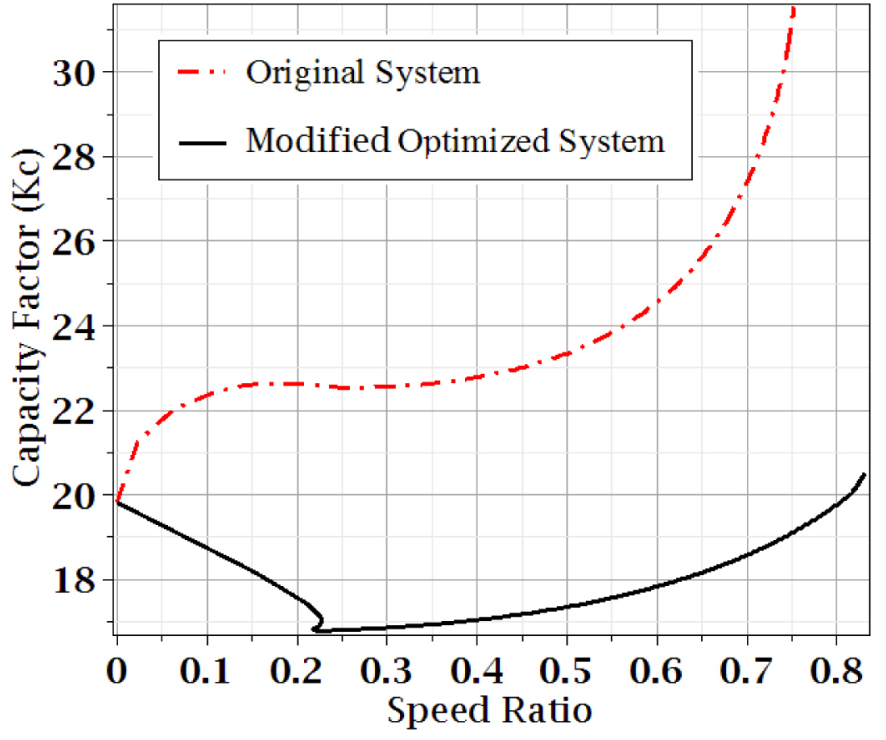

Figure 20. Capacity factor for the original and the optimized (equation (28)) system

\section{EFFECT OF THE PUMP EXIT ANGLE}

The exit vane angle of the pump is one of the important design parameters of a torque converter. In preliminary studies, it was considered as one of the design variables. However, the results showed that the objective function is related to the pump exit angle in a linear fashion. During the optimization iterations, the parameter settled to the value used by the original system, which was the lower limit of acceptable values.

\section{CONCLUSION}

We have performed symbolic sensitivity analysis on a model of a torque converter. The sensitivity analysis has allowed us to identify the radii of the torque converter elements, i.e. the pump, the turbine and the stator, the vane exit angle of the stator and the density of the hydraulic fluid to be more important than the other parameters of the model. Also a design optimization problem was solved, to minimize the loss of energy during the operation of the torque converter. Optimized values were obtained for the radii of the components and loss of energy was shown to have considerably reduced.

The study has identified the shock losses to be the dominant loss term for the system which was found to have decreased for the optimal set of parameters. On the other hand, the friction losses were found to have increased for the optimal parameters. However due to the dominance of the shock loss term the overall energy losses are reduced for the operation.

At this stage this analysis is based, on a slight approximation for the sensitivity analysis. We have assumed that, the leading term of eq. (17) is negligible compared to the other terms. Although this assumption is shown to be valid 
for this particular system, it is unreasonable to assume that, this would be universally acceptable. One possible way of addressing this issue would be, to include lock-up clutch dynamics into the system, which would enable us to simulate the system beyond the activation of the lock-up clutch. This way, a simulation can be run for a fixed duration, and the upper limit of the integration shown in equation (17), would become a constant. This would make the first term in equation (17) become zero and eliminate all concerns about the approximation. Future research on the topic will try to address this issue.

\section{ACKNOWLEDGEMENTS}

Financial support for this work has been provided by the Natural Sciences and Engineering Research Council of Canada (NSERC), Toyota, and Maplesoft.

\section{REFERENCES}

1. Hrovat, D. and Tobler, W. E., Bond Graph Modeling and Computer Simulation of Automotive Torque Converters, Journal of the Franklin Institute, Vol. 319, pp. 93-114, 1985.

2. Ishihara, T. and Emori, R., "Torque Converter as a Vibration Damper and Its Transient Characteristics," SAE Technical Paper 660368, 1966, doi: $10.4271 / 660368$.

3. Adibi Asl, H., Lashgarian Azad, N., and McPhee, J., "Math-Based Modeling and Parametric Sensitivity Analysis of Torque Converter Performance Characteristics," SAE Technical Paper 2011-01-0732, 2011, doi:10.4271/2011-01-0732.

4. Serban, R. and Freeman, J.S., Direct differentiation methods for the design sensitivity of multi-body dynamic systems, The 1996 ASME Design Engineering Technical Conferences and Computers in Engineering Conference, 18-22, 1996.

5. Smith, Eric D., Szidarovszky, F., Karnavas, W. J. and Bahill, A. T., "Sensitivity Analysis, a Powerful System Validation Technique", The Open Cybernetics and Systemics Journal, Vol. 2, pp 39-56, 2008.

6. Technical Articles, Toyota technical training series, Topics on automatic transmission, "Torque Converters", http://www.autoshop101.com/ forms/AT02.pdf (September 2011)

7. Wong, J.Y.. Theory of Ground Vehicles. John Wiley and Sons, Inc., New York, NY, second edition, 1993. 


\section{APPENDIX}

\section{APPENDIX A: MODEL PARAMETERS}

Table 2. Model parameters

\begin{tabular}{|c|c|c|c|}
\hline Name & Description & Value & Unit \\
\hline$\rho$ & Density of the hydraulic fluid & 840 & $\mathrm{Kg} / \mathrm{m}^{3}$ \\
\hline$I_{p}$ & Inertia of pump element & 0.106 & $\mathrm{Kg}-\mathrm{m}^{2}$ \\
\hline$I_{t}$ & Inertia of turbine element & 0.289 & $\mathrm{Kg}-\mathrm{m}^{2}$ \\
\hline$I_{s}$ & Inertia of stator element & 0.05 & $\mathrm{Kg}-\mathrm{m}^{2}$ \\
\hline$R_{p}$ & Radius of pump element & 0.115 & $\mathrm{~m}$ \\
\hline$R_{t}$ & Radius of turbine element & 0.068 & $\mathrm{~m}$ \\
\hline$R_{s}$ & Radius of stator element & 0.088 & $\mathrm{~m}$ \\
\hline$S_{p}$ & Design constant for pump & 0.0003 & $\mathrm{~m}^{2}$ \\
\hline$S_{t}$ & Design constant for turbine & 0.001 & $\mathrm{~m}^{2}$ \\
\hline$S_{s}$ & Design constant for stator & 0.001 & $\mathrm{~m}$ \\
\hline$\alpha_{p}$ & Vane blade exit angle in the pump & 0 & Deg \\
\hline$\alpha_{t}$ & Vane blade exit angle in the turbine & -58 & Deg \\
\hline$\alpha_{s}$ & Vane blade exit angle in the stator & 65 & Deg \\
\hline$\beta_{p}$ & Vane blade entry angle in the pump & -16 & Deg \\
\hline$\beta_{t}$ & Vane blade entry angle in the turbine & 48 & Deg \\
\hline$\beta_{s}$ & Vane blade entry angle in the stator & -30 & Deg \\
\hline$C_{f}$ & Friction loss factor & 0.2 & N/A \\
\hline$C_{s h}$ & Shock loss factor & 1 & N/A \\
\hline$L_{f}$ & Length of fluid inertia & 0.28 & $\mathrm{~m}$ \\
\hline$A$ & Flow area & 0.01 & $\mathrm{~m}{ }^{2}$ \\
\hline
\end{tabular}

\section{APPENDIX B: MATRIX FORM OF SYSTEM AND SENSITIVITY EQUATIONS}

\section{SYSTEM EQUATIONS}

The system is governed by a set of ordinary differential equations. They can be written in a matrix form as

$$
\mathbf{M} \dot{\mathbf{q}}=\mathbf{F}
$$


Where

$$
\begin{gathered}
\mathbf{M}=\left[\begin{array}{cccc}
I_{p} & 0 & 0 & \rho S_{p} \\
0 & I_{t} & 0 & \rho S_{t} \\
0 & 0 & I_{s} & \rho S_{s} \\
\rho S_{p} & \rho S_{t} & \rho S_{s} & \frac{\rho L_{f}}{A}
\end{array}\right] \\
\mathbf{q}=\left\{\begin{array}{llll}
\omega_{p} & \omega_{t} & \omega_{s} & Q
\end{array}\right\}^{T}
\end{gathered}
$$

And

$$
\begin{aligned}
& {\left[-\rho Q\left(\omega_{p} R_{p}^{2}+\frac{Q}{A} R_{p} \tan \alpha_{p}-\omega_{s} R_{s}^{2}-\frac{Q}{A} R_{s} \tan \alpha_{s}\right)+T_{p}\right.} \\
& -\rho Q\left(\omega_{t} R_{t}^{2}+\frac{Q}{A} R_{t} \tan \alpha_{t}-\omega_{p} R_{p}^{2}-\frac{Q}{A} R_{p} \tan \alpha_{p}\right)+T_{t} \\
& -\rho Q\left(\omega_{s} R_{s}^{2}+\frac{Q}{A} R_{s} \tan \alpha_{t}-\omega_{t} R_{t}^{2}-\frac{Q}{A} R_{t} \tan \alpha_{t}\right)+T_{s} \\
& \mathbf{F}=\left(\begin{array}{c}
\rho\left(\begin{array}{c}
\omega_{p}{ }^{2} R_{p}{ }^{2}+\omega_{t}{ }^{2} R_{t}^{2}+\omega_{s}{ }^{2} R_{s}^{2} \\
-\omega_{p} \omega_{t} R_{p}^{2}-\omega_{p} \omega_{s} R_{s}^{2}-\omega_{s} \omega_{t} R_{t}^{2}
\end{array}\right) \\
+\rho \frac{Q}{A}\left(\begin{array}{c}
\omega_{p}\left(R_{p} \tan \alpha_{p}-R_{s} \tan \alpha_{s}\right) \\
+\omega_{t}\left(R_{t} \tan \alpha_{t}-R_{p} \tan \alpha_{p}\right) \\
+\omega_{s}\left(R_{s} \tan \alpha_{s}-R_{t} \tan \alpha_{t}\right)
\end{array}\right) \\
-P_{L}(t)
\end{array}\right) \\
& P_{L}(t)=\frac{P_{s h}+P_{f}}{Q}
\end{aligned}
$$

\section{SENSITIVITY EQUATIONS}

Direct differentiation gives a set of ordinary differential equations known as the sensitivity equations. The system equations are combined with these sensitivity equations to form the augmented form of the equation, which can be written in matrix form as

$$
\underbrace{\left[\begin{array}{cc}
\mathbf{M}_{\mathrm{b}}^{4 \times 4}+\mathbf{P}^{4 \times 4} & \mathbf{M}^{4 \times 4} \\
\mathbf{M}^{4 \times 4} & 0^{4 \times 4}
\end{array}\right]}_{\Gamma} \overbrace{\left\{\begin{array}{c}
\dot{\mathbf{q}}^{4 \times 1} \\
\dot{\mathbf{q}}_{\mathrm{b}}^{4 \times 1}
\end{array}\right\}}^{\dot{\boldsymbol{q}}}=\underbrace{\left\{\begin{array}{c}
\mathbf{F}_{\mathrm{b}}+\mathbf{F}_{\mathbf{q}} \mathbf{q}_{\mathrm{b}} \\
\mathbf{F}
\end{array}\right\}}_{\boldsymbol{\Omega}}
$$


The actual expressions for these matrices depend on the identity of the model parameter $b$. If we perform sensitivity analysis with respect to the parameter $\rho$, the get the following matrices

$$
\begin{aligned}
& \Gamma=\left[\begin{array}{cccccccc}
0 & 0 & 0 & S_{p} & I_{p} & 0 & 0 & \rho S_{p} \\
0 & 0 & 0 & S_{t} & 0 & I_{t} & 0 & \rho S_{t} \\
0 & 0 & 0 & S_{s} & 0 & 0 & I_{s} & \rho S_{s} \\
S_{p} & S_{t} & S_{s} & \frac{L_{f}}{A} & \rho S_{p} & \rho S_{t} & \rho S_{s} & \frac{\rho L_{f}}{A} \\
I_{p} & 0 & 0 & \rho S_{p} & 0 & 0 & 0 & 0 \\
0 & I_{t} & 0 & \rho S_{t} & 0 & 0 & 0 & 0 \\
0 & 0 & I_{s} & \rho S_{s} & 0 & 0 & 0 & 0 \\
\rho S_{p} & \rho S_{t} & \rho S_{s} & \frac{\rho L_{f}}{A} & 0 & 0 & 0 & 0
\end{array}\right] \\
& \vartheta=\left\{\begin{array}{lllllllll}
\omega_{p} & \omega_{t} & \omega_{s} & Q & \omega_{p_{-}} \rho & \omega_{t_{-}} \rho & \omega_{s_{-}} \rho & Q_{-} \rho
\end{array}\right\}^{T} \\
& \omega_{p-} \rho=\frac{d}{d \rho}\left(\omega_{p}\right), \text { etc. }
\end{aligned}
$$

To express the vector $\boldsymbol{\Omega}$ we define the following sub expressions

$$
\begin{aligned}
& \psi_{0}=\left(\omega_{p}^{2} R_{p}^{2}+\omega_{t}^{2} R_{t}^{2}+\omega_{s}^{2} R_{s}^{2}-\omega_{p} \omega_{t} R_{p}^{2}-\omega_{p} \omega_{s} R_{s}^{2}-\omega_{s} \omega_{t} R_{t}^{2}\right) \\
& \psi_{1}=\left(\begin{array}{l}
2 R_{p}^{2} \omega_{p} \omega_{p-} \rho+2 R_{t}^{2} \omega_{t} \omega_{t-} \rho+2 R_{s}^{2} \omega_{s} \omega_{s-} \rho-\omega_{p-} \rho \omega_{t} R_{p}{ }^{2} \\
-\omega_{p} \omega_{t_{-}} \rho R_{p}{ }^{2}-\omega_{p_{-}} \rho \omega_{s} R_{s}{ }^{2}-\omega_{p} \omega_{s-} \rho R_{s}{ }^{2}-\omega_{s_{-}} \rho \omega_{t} R_{t}^{2}-\omega_{s} \omega_{t_{-}} \rho R_{t}^{2}
\end{array}\right) \\
& \psi_{2}=\left(\omega_{p}\left(R_{p} \tan \alpha_{p}-R_{s} \tan \alpha_{s}\right)+\omega_{t}\left(R_{t} \tan \alpha_{t}-R_{p} \tan \alpha_{p}\right)+\omega_{s}\left(R_{s} \tan \alpha_{s}-R_{t} \tan \alpha_{t}\right)\right) \\
& \psi_{3}=\left(\begin{array}{l}
\omega_{p} \rho\left(R_{p} \tan \alpha_{p}-R_{s} \tan \alpha_{s}\right)+\omega_{t} \rho\left(R_{t} \tan \alpha_{t}-R_{p} \tan \alpha_{p}\right) \\
+\omega_{s-} \rho\left(R_{s} \tan \alpha_{s}-R_{t} \tan \alpha_{t}\right)
\end{array}\right) \\
& \sigma_{1}=\left(\omega_{p} R_{p}^{2}+\frac{Q}{A} R_{p} \tan \alpha_{p}-\omega_{s} R_{s}^{2}-\frac{Q}{A} R_{s} \tan \alpha_{s}\right) \\
& \text { And } \quad \sigma_{2}=\left(\omega_{t} R_{t}^{2}+\frac{Q}{A} R_{t} \tan \alpha_{t}-\omega_{p} R_{p}^{2}-\frac{Q}{A} R_{p} \tan \alpha_{p}\right) \\
& \sigma_{3}=\left(\omega_{s} R_{s}^{2}+\frac{Q}{A} R_{s} \tan \alpha_{t}-\omega_{t} R_{t}^{2}-\frac{Q}{A} R_{t} \tan \alpha_{t}\right)
\end{aligned}
$$


In terms of these quantities we define the force vector

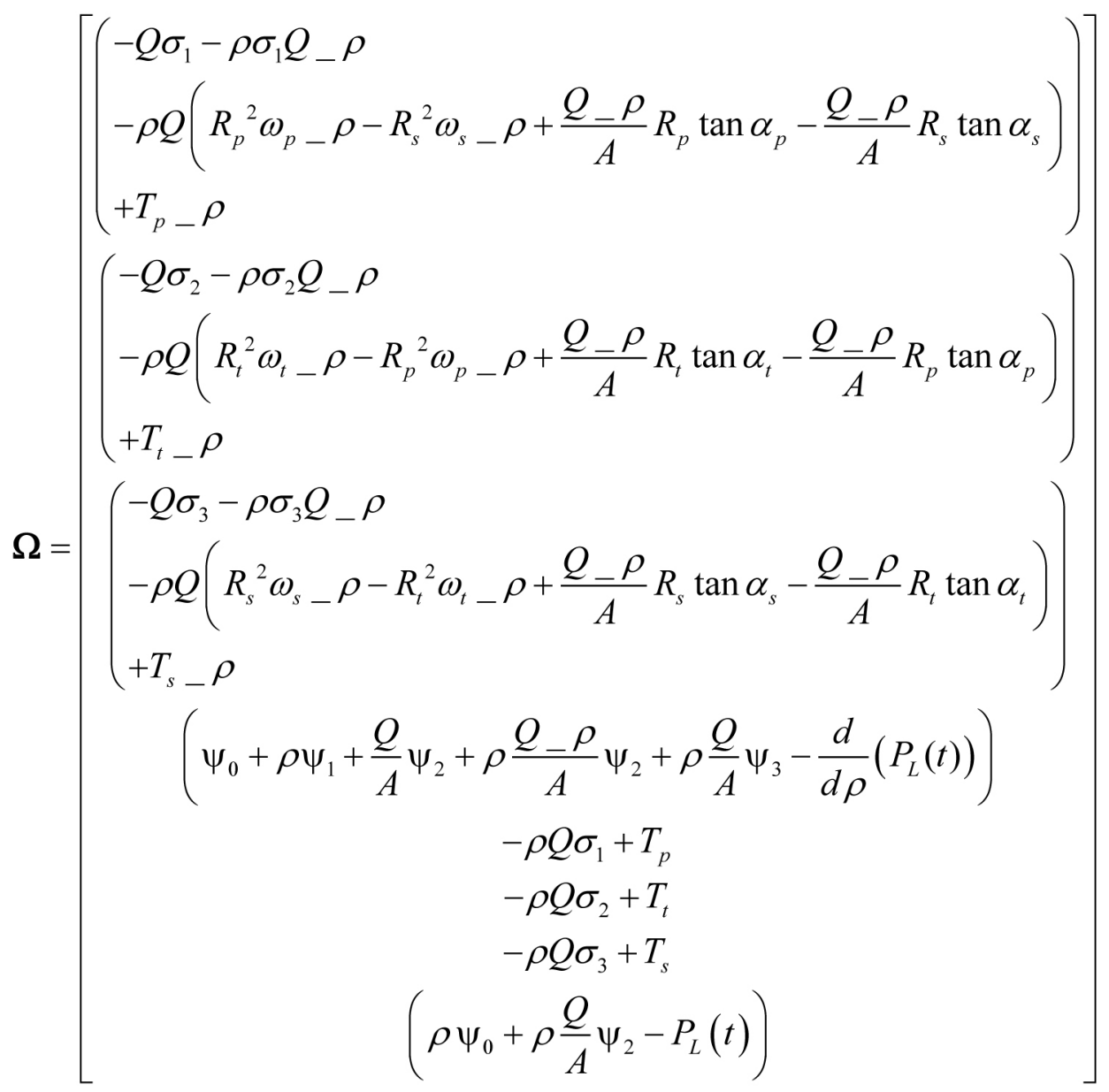

